WANL-TMI-162

July 26,1962

\title{
MODEL TESTING REQUIREMENTS
}

by

E. A. DeZubay

This report was prepared as an account of work sponsored by the United States Government. Neither the United States nor the United States Energy Research and Development Administration, nor any of their employees, nor any of their contractors, subcontractors, or their employees, makes any warranty, express or implied, or assumes any legal liability or responsibility for the accuracy, completeness

or usefulness of any information, apparatus, product or process disclosed, or represents that its use would not infringe privately owned rights.

Distribution:
W. H. Esselman
W. H. Arnold, Jr.
F. D. Retallick
A. B. Rothman
K. L. Rieke

G. R. Thomas

H. J. Fix

W. J. Havener

F. R. Spurrier

R. R. Holman 


\section{DISCLAIMER}

This report was prepared as an account of work sponsored by an agency of the United States Government. Neither the United States Government nor any agency Thereof, nor any of their employees, makes any warranty, express or implied, or assumes any legal liability or responsibility for the accuracy, completeness, or usefulness of any information, apparatus, product, or process disclosed, or represents that its use would not infringe privately owned rights. Reference herein to any specific commercial product, process, or service by trade name, trademark, manufacturer, or otherwise does not necessarily constitute or imply its endorsement, recommendation, or favoring by the United States Government or any agency thereof. The views and opinions of authors expressed herein do not necessarily state or reflect those of the United States Government or any agency thereof. 


\section{DISCLAIMER}

Portions of this document may be illegible in electronic image products. Images are produced from the best available original document. 
Page 1 of 8

\section{INTRODUCTION}

In the course of the development of components involving the flow of fluid, the question of the use of models arises frequently. The ability of a given model to predict the behavior of the prototype is always open to doubt. The discussion in the memorandum considers the various requirements which would have to be met in order to obtain meaningful information.

\section{DISCUSSION}

If the Navier Stokes equation is examined, three types of terms become apparent.

Writing this equation as:

$$
\rho\left(\frac{\partial u}{\partial t}+u \frac{\partial u}{\partial x}+v \frac{\partial u}{\partial y}+w \frac{\partial u}{\partial z}\right)=\frac{-\partial}{\partial x}(p+\rho g h)+\mu \nabla^{2} u
$$

the inertial or $D^{\prime}$ Alembert forces are composed of the expanded terms of $\rho \frac{D u}{D t}$; the pressure forces are $\frac{\partial}{\partial x}(p+\rho g h)$; and the viscous forces, $\mu \nabla^{2}$ u. Hence in terms of gross parameters $\Delta P, V, L, h$ (in a given direction):

1. Inertia force $\approx \rho u \frac{\partial u}{\partial x} \approx \rho V \frac{V}{L}$,

2. Pressure force $\approx \frac{\partial p}{\partial x} \approx \frac{\Delta P}{L}$,

3. Viscous force $\approx \mu \nabla^{2} u \approx \mu \frac{V}{L^{2}}$,

4. Gravity forces $\approx \frac{\partial}{\partial x}(\rho g h) \approx \rho g \frac{L}{L} \approx \rho g$

The ratio of the inertial to the viscous force yields the familiar term $\rho \frac{V^{2}}{L} \div \frac{\mu V}{L^{2}}=\rho \frac{V L}{\mu}$ easily recognized as the Reynolds number. The ratio of the pressure to inertial force yield the 
term $\frac{\Delta P}{L} \div \rho \frac{V^{2}}{L}=\frac{\Delta P}{\rho V^{2}}$, which, with the exception of a length to diameter term is proportional to the Fanning friction term. The ratio of inertia forces to gravitational force yield $\rho \frac{V^{2}}{L} \div \rho g=\frac{V^{2}}{g L}$ commonly referred to as the Froud number. For gaseous flow, the significance of this term is trivial since variations in pressure usually exceed variations in elevation by orders of magnitude. Compressibility considerations can be obtained from the energy equation

$$
u d u+C_{p} d T=0
$$

The ratio of the kinetic term udu to the potential term $C_{p} d T$ leads to $V^{2} / T$ which can be interpreted as the Mach number. Hence a three variable reference plane would be required with the axes of Reynolds number, Mach number and the dimensionless pressure drop $\left(\Delta P / \rho V^{2}\right)$.

In order to duplicate the three dimensionless number in two systems denoted by subscripts $x$ and $y$ the following condition must be met:

For Reynolds number:

$$
\operatorname{Re}=\frac{V_{x} L_{x} P_{x}}{\mu_{x}}=\frac{V_{y} L_{y} P_{y}}{\mu_{y}}
$$

For Mach number:

$$
M=\frac{v_{x}}{\left(\frac{k_{x} g R T_{x}}{m_{x}}\right)^{1 / 2}}=\frac{v_{y}}{\left(\frac{k_{y} g R T_{y}}{m_{y}}\right)^{1 / 2}}
$$


Page 3 of $\underline{8}$

For pressure drop:

$$
I I=\frac{\Delta P_{x}}{\rho_{x} v_{x}^{2}}=\frac{\Delta P_{y}}{\rho_{y} v_{y}^{2}}
$$

Using a general continuity relation that the mass rate of flow $\dot{w}$ is the product of an area represented by the square of a characteristic dimension $L$, the velocity and the density

$$
\dot{w}=L^{2} \vee \rho
$$

permits the reduction of the dimensionless variables $(R e, M$. II) to

$$
\operatorname{Re}=\frac{\dot{w}_{x}}{L_{x} \mu_{x}}=\frac{\dot{w}_{y}}{L_{y} \mu_{y}}
$$

which reduced to

$$
\begin{gathered}
\dot{w}_{x}=\left(\frac{L_{x}}{L_{y}}\right)\left(\frac{\mu_{x}}{\mu_{y}}\right) \dot{w}_{y} \\
M=\frac{\frac{\dot{w}_{x}}{L_{x}^{2} \rho_{x}}}{\left(\frac{k_{x} g R T_{x}}{m_{x}}\right)^{1 / 2}}=\frac{\frac{\dot{w}_{y}}{L_{y}^{2} \rho_{y}}}{\left(\frac{k_{y} g R T_{y}}{m_{y}}\right)^{1 / 2}}
\end{gathered}
$$

and remembering $\rho=\frac{m P}{g R T}$ and $k_{x}=k_{y}$ (if gases having the same number of atoris per molecule are used) the simplification can be made that: 
Page 4 of 8

$$
\dot{w}_{x}=\left(\frac{L_{x}}{L_{y}}\right)^{2} \frac{P_{x}}{P_{y}}\left(\frac{m_{x}}{m_{y}} \frac{T_{y}}{T_{x}}\right)^{1 / 2} \dot{w}_{y} .
$$

The pressure drop can be expressed as

$$
I=\frac{\Delta P_{x} L_{x}^{4} P_{x}}{\dot{w}_{x}^{2}}=\frac{\Delta P_{y} L_{y}^{4} \rho_{y}}{\dot{w}_{y}^{2}}
$$

which can be reduced to

$$
\Delta P_{x}=\left(\frac{\dot{w}_{x}}{\dot{w}_{y}}\right)^{2}\left(\frac{L_{y}}{L_{x}}\right)^{4} \frac{P_{y}}{P_{x}} \frac{m_{y}}{m_{x}} \frac{T_{x}}{T_{y}} \quad \Delta P_{y}
$$

The elimination of $\left(\frac{\dot{w}_{x}}{\dot{w}_{y}}\right)$ between 2.02 and 3.02 yields

$$
\frac{\Delta P_{x}}{\Delta P_{y}}=\frac{P_{x}}{P_{y}}
$$

while the elimination of $\left(\frac{\dot{w}_{x}}{\dot{w}_{y}}\right)$ between 1.02 and 2.02 yields

$$
\frac{P_{x}}{P_{y}}=\frac{L_{y}}{L_{x}} \frac{\mu_{x}}{\mu_{y}}\left(\frac{m_{y}}{m_{x}} \frac{T_{x}}{T_{y}}\right)^{1 / 2}
$$




\section{Page 5 of 8}

Since the purpose of the model testing is the flow simulation of hydrogen at high pressure and low temperature with a fluid at a pressure level near atmospheric and at a reasonable temperature level, a wide range of fluids can be considered. Ideally a full scale model would be desired since a prototype of the actual component could be used. The last condition corresponds to a scale factor of unity $\left(L_{X} / L_{y}=1\right)$ and temperature ranges of hydrogen would be between $30^{\circ} R$ and $200^{\circ} \mathrm{R}$ compared to a simulator gas temperature range from 500 to $1000^{\circ} \mathrm{R}$. Nominally setting the hydrogen gas temperature at $150^{\circ} R$ and designating hydrogen as gas " $y$ ", hereafter used with subscript "h", we have for the Reynolds number condition (equation 1.02):

$$
\dot{w}_{x}=\frac{\mu_{x}}{\mu_{h}} \dot{w}_{h}
$$

For air at $530^{\circ} \mathrm{R}$ this becomes:

$$
\dot{w}_{x}=5 \dot{w}_{h}
$$

That is, five times the mass flow of air is required to simulate the mass flow of hydrogen. A reduction can be obtained by using cold nitrogen (Table 1) but even with cold nitrogen twice the mass flow is required to simulate the flow of hydrogen. The use of liquids aggrevate the problem of high mass flows. From a practical viewpoint very little could be gained by using . another fluid (cold $\mathrm{N}_{2}$, methane, etc.) when the addition complexities of a closed system are considered. 
Page 6 of 8

The numerics for simultaneous simulation of Reynolds and Mach number yield (equation 3.04):

$$
\frac{P_{x}}{P_{h}}=2.47
$$

Using this pressure ratio, equation 3.03 reduces to:

$$
\Delta P_{X}=2.47 \Delta P_{h}
$$

A full scale model could then be tested with air under identical Reynolds, Mach and pressure drop dimensionless numbers under the assumed conditions $\left(\mathrm{H}_{2}\right.$ at $150^{\circ} \mathrm{R}$, Air at $530^{\circ} \mathrm{R}$ ), but on examination of the flow and pressures involved (Table 2) equipment of heroic proportions would be required.

As Table 2 indicates, the flow and pressure requirements which respectively simulate the Reynolds and Mach number (equations 1.03 and 2.03 respectively) would require very large air supplies at high pressures, but would result in very reasonable pressure drops (equation 3. 03). If compressibility effects are not expected to be serious, lower pressure ratios than that required to satisfy 1.03 and 2.03 simultaneously can be used. In the event 
that compressibility effects are small so that they can either be neglected or that suitable corrections* can be used, the pressure drop term can be written as (numeric substitution in 3. 02)

$$
\Delta P_{x}=6.10 \frac{P_{h}}{P_{x}} \Delta P_{h}
$$

The pressure drop can be scaled arbitrarily by the choice of the pressure ratio. This approach does permit an additional degree of freedom in the design of simulation tests.

Reducing the scale factor $\left(L_{X} / L_{h}<1.0\right)$ reduces the flow requirements but increases the required pressure level. Table 3 presents the flow and pressure requirements for a one tenth scale model $\left(L_{X} / L_{y}=0.1\right)$. The comparison of quantities required and pressure levels expected under such a scaled condition with a full sized model is not encouraging. The

*The pressure drop term $\Delta P$ could probably be replaced by its compressible equivalent $\Delta P /\left(1+\frac{M^{2}}{4}\right)$ which stems from the general. series:

$$
\frac{\Delta P}{\rho V^{2}}=1 / 2\left[1=\frac{1}{4} M^{2}+\frac{2-k}{24} M^{4}+\frac{(2-k)(3-2 k)}{192} M^{6} \ldots\right]
$$

(See H. W. Liepman and A. E. Pucket "Aerodynamics of a Compressible Fluid" p. 27;

Wiley 1947) 


\section{Page 8 of 8}

pressure level requirement will be extrem, ly difficult to meet, so the Mach effects will be difficult to model.

From the considerations of similitude it becomes apparent that best simulation would be accomplished with the largest possible air supply at the highest reasonable pressure. The degree of compromise required by economic considerations will determine the degree of compromise in simulation. 


\section{TABLE 1}

FLUID

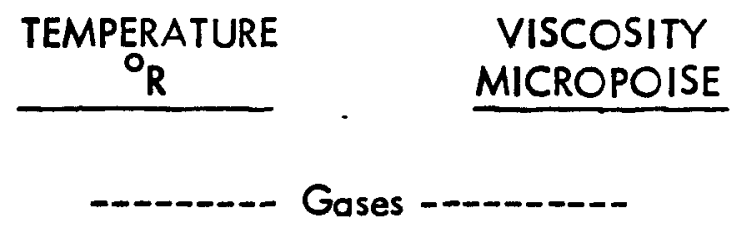

$\underline{\mu_{x} / \mu_{h}}$

150

36

1.00

Air

530

1000

180

263

5. 00

7.30

Argon

530

221

6.14

$\mathrm{CO}_{2}$

530

148

4. 11

$\mathrm{Cl}$

530

133

3. 70

$\mathrm{He}$

530

194

5. 39

$\mathrm{CH}_{4}$

530

108

3. 00

Steam

672

125

3.47

$N_{2}$

180

68

1.89

-_-_--- Liquids

Methyl Alcohol

Acetone

Glycerine

Water
530

530

530

530
6,000

3,200

$1.49 \times 10^{9}$

10,000
167.0

88. 8

$4.1 \times 10^{7}$

277.8 
TABLE 2

For Full Scale Model $\left(L_{x} / L_{h}=1\right)$

Hydrogen Flows $\left(\dot{w}_{h}\right)$

Air "Simulator" Flows $\left(\dot{w}_{x}\right)$

1 pps
$10 \mathrm{pps}$
$100 \mathrm{pps}$

Hydrogen Pressure Level $\left(P_{h}\right)$

15 psia

450 psia

1500 psia

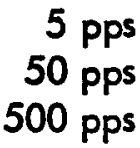

Air Pressure Level

37 psia

1111 psia

3705 psia

\section{TABLE 3}

For Small Scale Model $\left(L_{x} / L_{h}=0.10\right)$

Hydrogen Flows $\left(\dot{w}_{h}\right)$

$$
\begin{array}{r}
1 \mathrm{pps} \\
10 \mathrm{pps} \\
100 \mathrm{pps}
\end{array}
$$

Hydrogen Pressure Level $\left(P_{h}\right)$
Air "Simulator" Flows $\left(\dot{w}_{x}\right)$

\section{5 pps}

- $5.0 \mathrm{pps}$

50.0 pps

Air Pressure Level

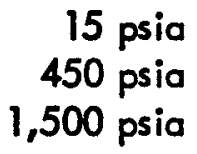

370 psia

11,111 psia

37,050 psia 


\begin{tabular}{|c|c|c|}
\hline$C_{p}$ & $\begin{array}{l}= \\
=\end{array}$ & $\begin{array}{l}\text { Specific heat at constant pressure } \\
\text { Gravitational constant }\end{array}$ \\
\hline h & $=$ & Heighth \\
\hline k & $=$ & Ratio of specific heats \\
\hline$L$ & $=$ & Length \\
\hline m & $=$ & Molecular weight \\
\hline M & $=$ & Mach number \\
\hline $\mathbf{P}$ & $=$ & Pressure \\
\hline$\Delta P$ & $=$ & Pressure difference \\
\hline $\mathbf{R}$ & $=$ & Universal gas constant \\
\hline+ & $=$ & Time \\
\hline$T$ & $=$ & Temperature \\
\hline$u$ & $=$ & Velocity component in $x$ direction \\
\hline $\mathbf{v}$ & $=$ & Velocity component in y direction \\
\hline V & $=$ & Mean velocity \\
\hline w & $=$ & Velocity component in z direction \\
\hline$x$ & $=$ & Cartesian coordinates \\
\hline y & $=$ & Cartesian coordinates \\
\hline $\mathbf{z}$ & $=$ & Cartesian coordinates \\
\hline$\dot{w}$ & $=$ & Mass flow rate \\
\hline$\mu$ & $=$ & Viscosity \\
\hline II & $=$ & $\begin{array}{c}\text { Dimensionless pressure drop } \\
.\end{array}$ \\
\hline \multicolumn{3}{|c|}{ Subscripts } \\
\hline h & $=$ & Pertaining to hydrogen \\
\hline$x$ & $=$ & Pertaining to gas $x$ \\
\hline$y$ & $=$ & Pertaining to gas $y$ \\
\hline
\end{tabular}

